\title{
MAINTENANCE SUPPORT SYSTEM FOR RECONFIGURABLE MANUFACTURING SYSTEMS
}

\author{
Miroslav Rakyta, Miroslav Fusko, Michal Haluška, Patrik Grznár \\ University of Zilina, Univerzitna 8215/1, 01026 Zilina, Slovak Republic
}

\begin{abstract}
The maintenance process is one of the most important elements within the overall scope of plant and facilities engineering function. It is a broad-based technology area for the industrial, commercial, institutional, and business communities. The broad scope of plant and facilities engineering is continuously changing and growing in importance as a key contributor to the success of a total operation. Elements within it, such as maintenance, energy management and regulatory compliance, have all evolved to new levels of importance for the total operation.
\end{abstract}

Keywords: technical services; intelligent agents; maintenance; reconfigurable maintenance systems
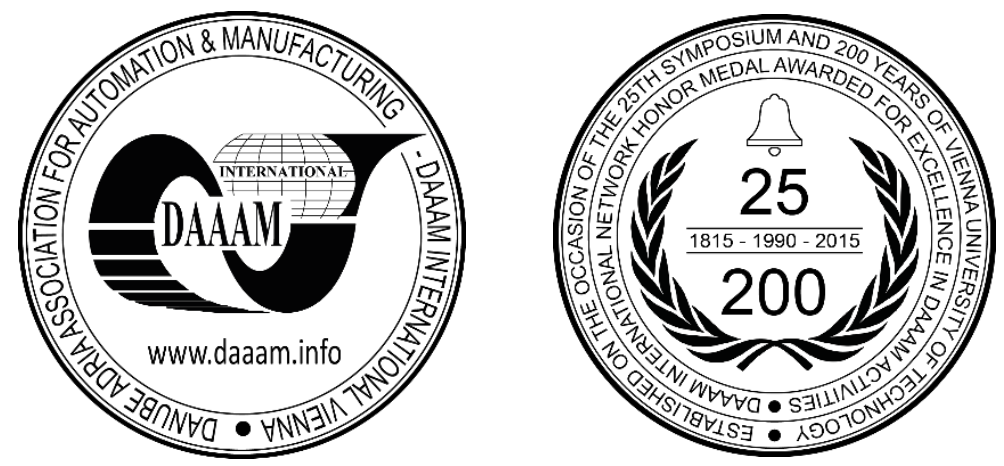

This Publication has to be referred as: Rakyta, M[iroslav]; Fusko, M[iroslav]; Haluska, M[ichal] \& Grznar, P[atrik] (2016). Maintenance Support System for Reconfigurable Manufacturing Systems, Proceedings of the 26th DAAAM International Symposium, pp.1102-1108, B. Katalinic (Ed.), Published by DAAAM International, ISBN 978-3-90273407-5, ISSN 1726-9679, Vienna, Austria

DOI: $10.2507 / 26$ th.daaam.proceedings. 155 


\section{Maintenance as an internal business opportunity and profit center}

Traditional thinking about maintenance has changed dramatically. Maintenance was once considered a necessary evil, but it is now being viewed as a key contributor to profit in a manufacturing or service providing operation. For example, what if the net profit ratio of an operation is $4 \%$ ? What does a $4 \%$ net profit ratio mean in terms of the amount of equivalent sales needed to generate profits? A net profit ratio of $4 \%$ requires $25 €$ of equivalent sales for each $1 €$ of net profit generated. [6] Therefore, when we view maintenance in these terms, we can readily see that a small savings in maintenance can mean a great deal to the bottom line and equivalent sales. From Table 1, maintenance as a profit center is illustrated, showing that only a 40,000 € savings is required to translate into the equivalent of $1,000,000 €$ in sales. There are many more areas, such as the value of increased asset uptime, increased net capacity and just-in-time throughput, increased product quality and increased customer service, that all contribute to the bottom line and subsequently to profit. [8], [20]

\begin{tabular}{ll}
\hline $\begin{array}{l}\text { Maintenance Savings to } \\
\text { Impact Net Profit }(€)\end{array}$ & $\begin{array}{l}\text { Equivalent Sales Required for } \\
\text { Generating Net Profit }(€)\end{array}$ \\
\hline 1 & 25 \\
1,000 & 25,000 \\
10,000 & 250,000 \\
20,000 & 500,000 \\
30,000 & 750,000 \\
40,000 & $1,000,000$ \\
80,000 & $2,000,000$ \\
120,000 & $3,000,000$ \\
200,000 & $5,000,000$ \\
\hline
\end{tabular}

Table 1. Maintenance as a Profit Center.

There is currently no support system, able to respond effectively to adverse conditions in the production system. Therefore, it is necessary to probe more deeply the reconfiguration production systems through which it can make changes for the purpose of cost-effective elimination of adverse evolving conditions in the production system.

Reconfigurable systems present new challenges for cost-effective implementation of maintenance activities with quick response processes occurring in the system abnormality. Such systems must be designed so that, they can perform all the required functions with high reliability of response to changing system conditions. Therefore need to paid to the rights of proposed maintenance policies, whose purpose is to contribute to the system reconfigurable with respect to production throughput times and reliable performance of the required system functions. [18]

\section{Maintenance for reconfigurable manufacturing systems}

Manufacturing environment provides during the production period variable values, which must be extracted into the desired form. Sensors must ensure collection of required data, which are subsequently evaluated on the basis of stated variables. With the help of maintenance system in reconfigurable manufacturing system we can minimize the total costs which are related with downtime. [3]

\subsection{Maintenance policy}

The main role of the reconfiguration is to improve the system throughput and reduce the probability of system failure, while the disadvantage is the cost incurred for the requested transfer (Fig. 1). For an optimal compromise between those aspects of the reconfiguration, it is necessary to implement maintenance policy to maintenance system with decision-making process for support reconfiguration. [10]

The proposed policy consists of following actions: [17]

- Preventive repairs - are carried out by prognostic module which predicts possible failures of the production configuration of machines and equipment. Repairs are carried out through the interaction of intelligent agents that share data and events. [21]

- Reactive repair - repair performed because of an unexpected failure of production components. Unfavorable situation of that magnitude can occur in the time interval between preventive repairs.

- Reconfiguration - initialization lies in elimination of the adverse conditions as well as in achieving the desired of system reliability.

The principles of corrective actions implementation for potential errors removal: [19] 
- Performing of preventive repair if the time period of facilities is nearing failure (prognostic model).

- During an accidental failure immediate actions are required to ensure production activities continuity.

Corrective actions should be carried out through the transfer of reconfiguration requirements which are based on the following assumptions: [11]

- If the states of system configuration are changing. During changes it is needed to control relevance of the current operating mode with preferred system model.

- If the reliability of the current system is greater or equal to defined boundary. Then it is necessary to reconfigure the system to a preferred mode of operation.

Reconfiguration is not necessary if the current system reliability is less than the defined boundary. Threshold reliability value should initiate reconfiguration activities. Measuring activities are based on extraction and simulation of process data.

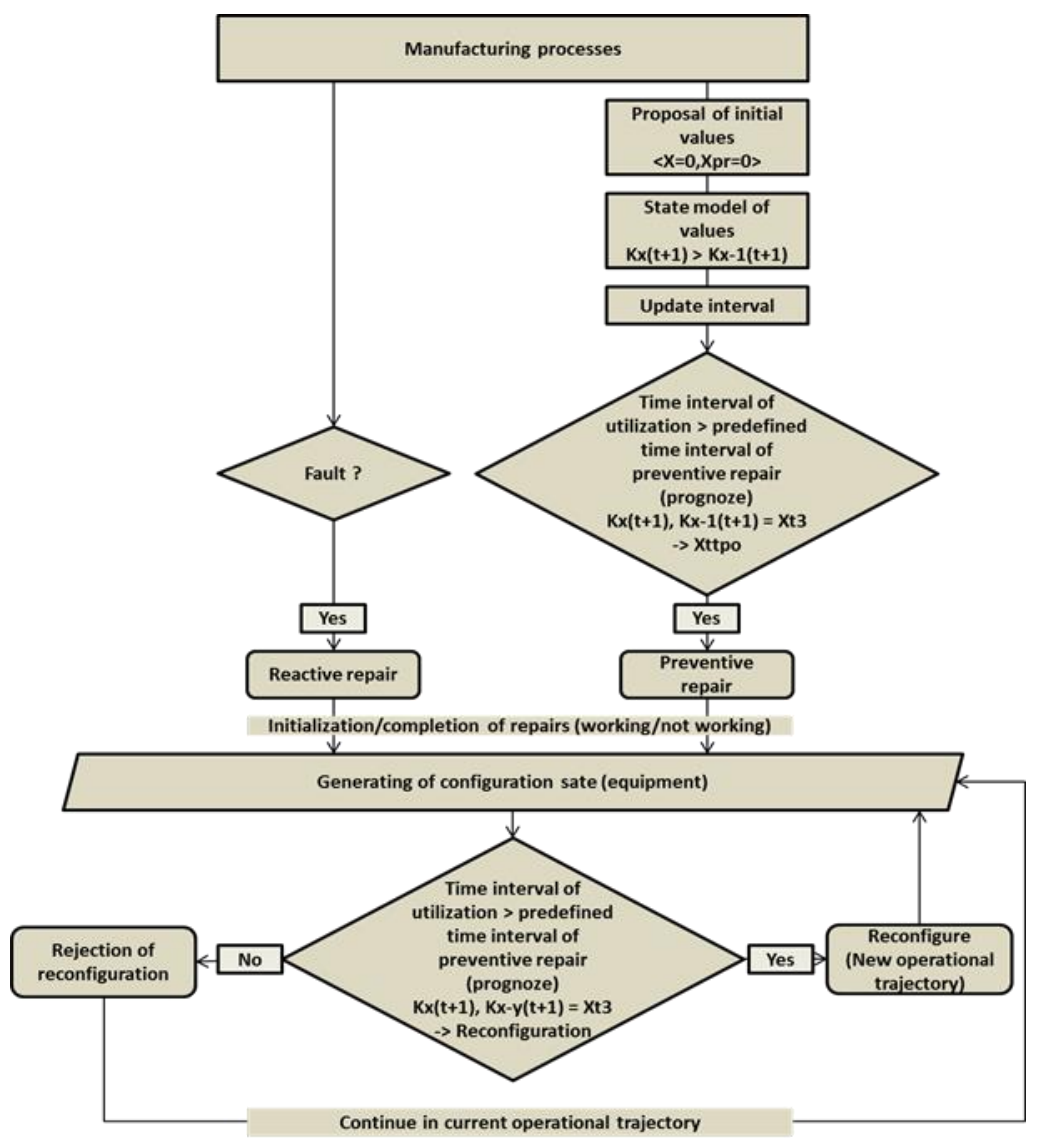

Fig. 1. Maintenance policy in the field of reconfigurable manufacturing systems.

Maintenance policy for reconfigurable manufacturing systems can be used in transfer lines for change of operational trajectory. During generating faults is possible within proposed policy omit part of operational trajectory on which is identified fault and consequently reconfiguration of system so that this part of trajectory is replaced by a new trajectory with a view to maintaining required sequence of operations. This means that the trajectory can be changed only if it is in manufacturing system, there are other tools that can perform the desired operation. This means that the trajectory can be changed only if they are in manufacturing system machines which can perform required operation. [12], [1]

\subsection{Functional principles of maintenance system}

Diagnostic modulator must provide the user of information about the fault occurs and too monitoring the current system data reliability. On the basis of the monitoring activities may be implemented corrective measures to ensure the required system reliability. It is necessary constantly monitor the values $\mathrm{KX}-1(\mathrm{t}+1), \mathrm{kX}-\mathrm{y}(\mathrm{t}+1), \mathrm{KX}(\mathrm{T}+1)$ and verify them by means of the output device. It is necessary for the early identification of abnormalities that are subject to the generation of possible failure. [4] 
Frequent failures occurring during the start-up period of the new production configuration and they should be not preventive removed. It is for this reason necessary to initialize reconfiguration activities for the optimum setting of the configuration. On the basis of the facts it is necessary during the ramp-time period to carry out reactive repairs. Agent control can ensure reliable preventive repair and reconfiguration of manufacturing system on the basis of generation adverse conditions. Process agent represents production facilities that perform desired operation. Agent can through the transfer of data units and occurrence events provides sensor agent data which must be through algorithmic calculations converted into the desired structure. Modified data are through the agent's abilities transferred to detection module which is represented by a respective agent. Simulation agent enables on the bases of initialization process activities their abilities which are subject to simulation activities. Simulation outputs must be extracted through an agent and then send to the detection agent. The detection agent on the basis of these assumptions identifies abnormalities and generates states. [13]

The ability of diagnostic agent is used by predictive agent who predicts potential faults and degradation of the current configuration and provides this knowledge to diagnostic agent who has pursued his corrective measures. Decision agent identifies possible faults and performs remedial actions associated with preventive repairs and reconfiguration of manufacturing system. [14]

During recording of sensor data are generate events which triggered activation of simulation mechanism. The role of the simulator is to ensure the extraction of experimental values for diagnostic operations on the basis of the data recording from the real environment. The mechanism should integrate simulation models whose selection is dependent on the relevant data. Data from the individual modules are subsequently analysed by a diagnostic agent, which has integrated recalculation algorithms for generating functions (Fig. 2). Transformation of data from the real environment can be expressed as follows: [9]

$$
\mathrm{Kx}-1(\mathrm{t}+1)=\mathrm{f} 1(\mathrm{Kx}-1)(\mathrm{t})+\mathrm{n}(\mathrm{t})
$$

Data record from the manufacturing environment during the time periods ( $\mathrm{kx}-1$ for module)

$$
K x-y(t+1)=f 2((K x-y)(t)+n(t)
$$

Data record from the manufacturing environment during time periods ( $\mathrm{kx}-\mathrm{y}$ for all system modules)

$$
\mathrm{Kx}(\mathrm{t}+1)=\mathrm{f} 3(\mathrm{Kx}(\mathrm{t})+\mathrm{n}(\mathrm{t}))
$$

Collection of data from the simulation model during the time periods (Kx for simulator)

During the time periods $t$ interdependencies between functional values are generated. They must meet specific requirements. If dependency $\mathrm{f} 1(\mathrm{Kx}-1) \mathrm{t}+\mathrm{n}(\mathrm{t})>\mathrm{f} 3(\mathrm{Kx}(\mathrm{t})+\mathrm{n}(\mathrm{t}))$ is fulfilled, the device does not meet the required reliability and on the basis of this argument it is necessary to configure the modular kit by intelligent agents. [23]

The state $\mathrm{f} 2((\mathrm{Kx}-\mathrm{y})(\mathrm{t})+\mathrm{n}(\mathrm{t}))>\mathrm{f} 3(\mathrm{Kx}(\mathrm{t})+\mathrm{n}(\mathrm{t}))$ represents the total unreliability of production configuration due to generating of a large number of abnormalities. Consequently, it is necessary to initialize the reconfiguration activities. These assumptions result from the generating of tates of device configuration during the production period. Due to this fact it is necessary to initialize the reconfiguration activities to ensure transfer requirements for optimizing operational trajectories. This fact is based on the assumption that the values of function $f 1((K x-1) t+n(t)), f 2((K x-y)(t)+n(t))=$ $\mathrm{f} 3(\mathrm{Kx}(\mathrm{t})+\mathrm{n}(\mathrm{t}))=$ const., This state covers a reliable operation of the production configuration. [7] 

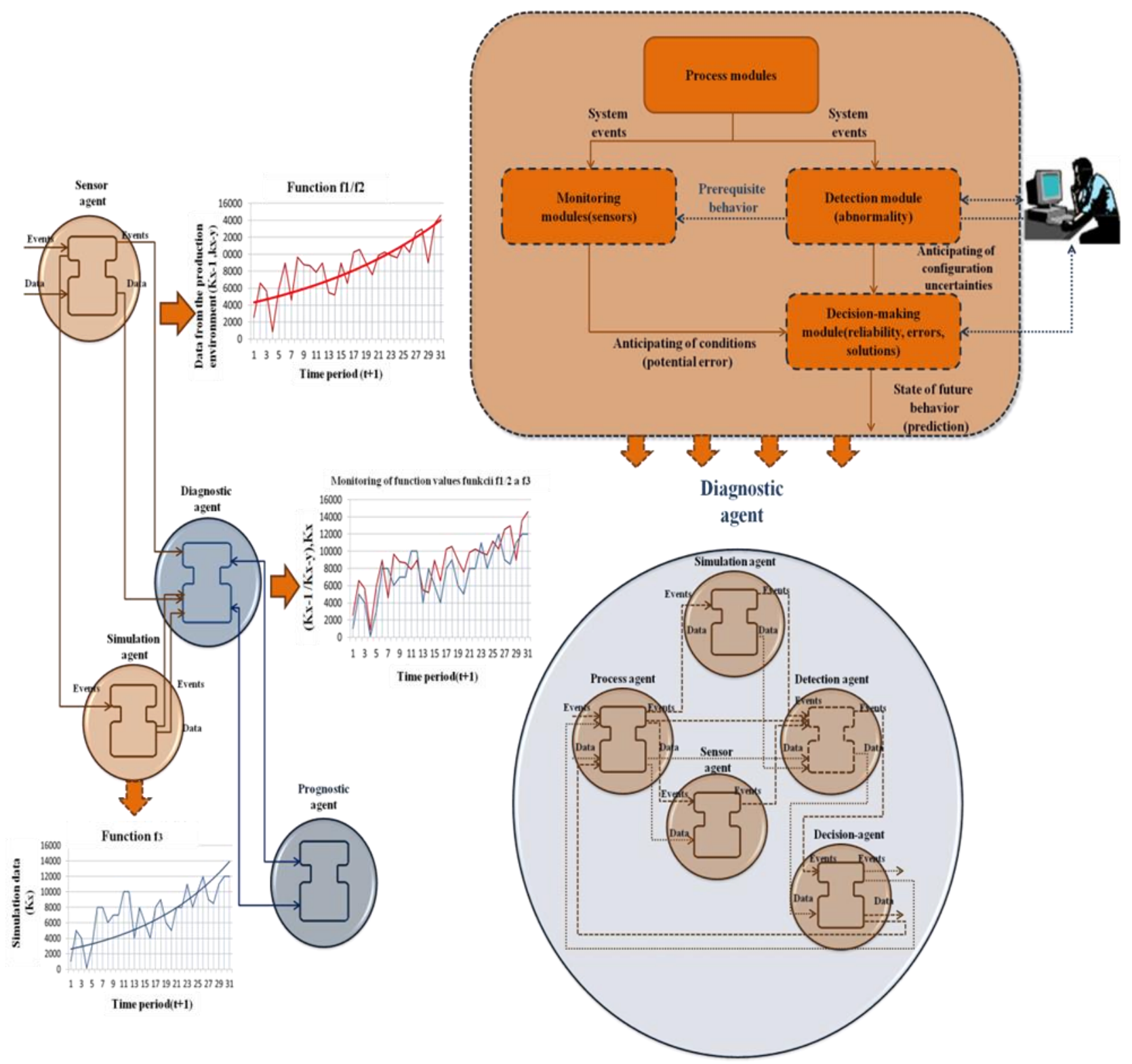

Fig. 2. Automated fault diagnostic.

During the time periods $t$ interdependencies between functional values are generated. They must meet specific requirements. If dependency $\mathrm{f} 1(\mathrm{Kx}-1) \mathrm{t}+\mathrm{n}(\mathrm{t})>\mathrm{f} 3(\mathrm{Kx}(\mathrm{t})+\mathrm{n}(\mathrm{t}))$ is fulfilled, the device does not meet the required reliability and on the basis of this argument it is necessary to configure the modular kit by intelligent agents. [23]

The state $\mathrm{f} 2((\mathrm{Kx}-\mathrm{y})(\mathrm{t})+\mathrm{n}(\mathrm{t}))>\mathrm{f} 3(\mathrm{Kx}(\mathrm{t})+\mathrm{n}(\mathrm{t}))$ represents the total unreliability of production configuration due to generating of a large number of abnormalities. Consequently, it is necessary to initialize the reconfiguration activities. These assumptions result from the generating of tates of device configuration during the production period. Due to this fact it is necessary to initialize the reconfiguration activities to ensure transfer requirements for optimizing operational trajectories. This fact is based on the assumption that the values of function $\mathrm{f} 1((\mathrm{Kx}-1) \mathrm{t}+\mathrm{n}(\mathrm{t}))$, $\mathrm{f} 2((\mathrm{Kx}-\mathrm{y})(\mathrm{t})+\mathrm{n}(\mathrm{t}))=$ $\mathrm{f} 3(\mathrm{Kx}(\mathrm{t})+\mathrm{n}(\mathrm{t}))=$ const., This state covers a reliable operation of the production configuration. [7]

\subsection{Failure prediction}

Prognostic modulator must (Fig. 3) predict future system behaviour, which is influenced by the intensity of generated errors. The default threshold time period Dtt is determined on the basis of the production program, which is influenced by production process abnormalities. For aggregated sensor data and simulation parameters is needed transformation of values into the function $\mathrm{fp}$, which represents a graphical development of increasing probability of failure. The function can be expressed as follows: [16]

$$
\mathrm{d}((\mathrm{Kx}-1),(\mathrm{Kx}-\mathrm{y}), \mathrm{Kx}) / \mathrm{dt}=\mathrm{fp}(\mathrm{t}, \mathrm{Kx}-1, \mathrm{Kx}-\mathrm{y}, \mathrm{Kx})
$$


This function (4) is used to predict future behavior of production facilities, as well as manufacturing configuration. The frequency of faults increases incrementally and therefore it is needed to activate reconfiguration activities which reduce the likelihood of subsequent failure. Failure function $\mathrm{f} 3$ represents simulation data, while the functions $\mathrm{f} 1$ and $\mathrm{f} 2$ include data transferred from the physical modules. Under this initiative it is necessary to determine the probable failure Xpp2 which has an associated weight Vttf which covers the time to failure. By the previous faults can be determined point of weight Bttfn. System will predict point of potential fault with the help of this principle. [5]

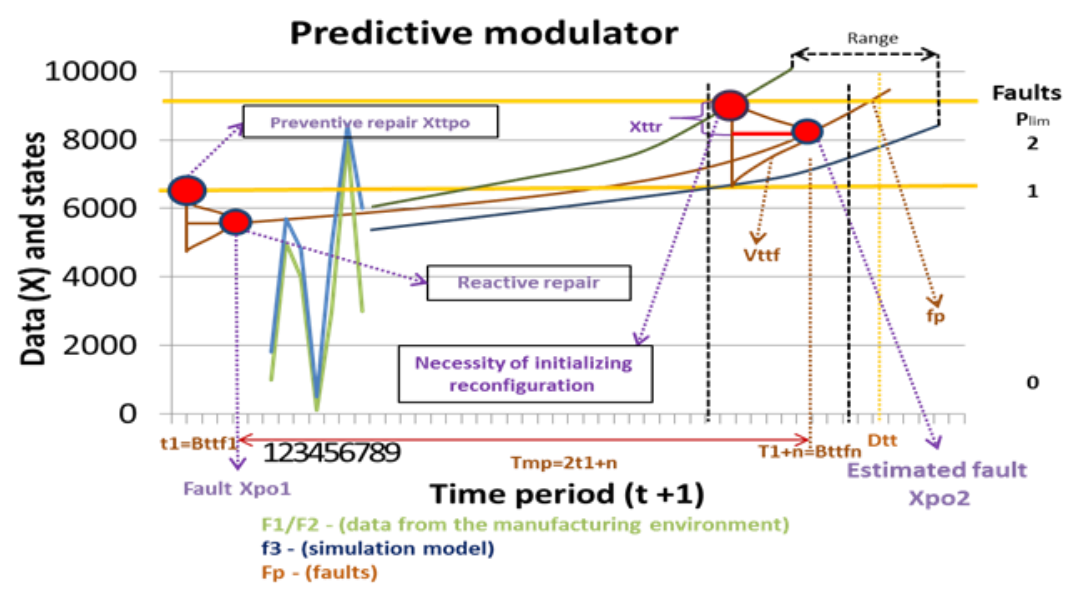

Fig. 3. Prognostic model representing predicted failures and the time intervals for the implementation of corrective actions.

Plim value is defined as the time between failures tmp during the life cycle of configuration. The time interval Xttr represents initialization of reconfiguration and its progress which is dependent on incurred faults. Reactive repair must be initialized when system does not provide enough capabilities. These faults are emerging mostly during the rampup period. Therefore it is needed to activate calibration activities through cyclic reconfiguration and during the manufacturing operations execute preventive repairs. [2]

Reconfiguration must be in this case based on the change of operational trajectory in manufacturing system. A fault occurs only if the mentioned value has not been identified. The reactive repairs must be initialized only if it has not been identified value of data for the needs of reconfiguration which are related to the current manufacturing system reliability. [15]

\section{Conclusion}

In this article are described components of proposed reconfigurable system. The article also shows the necessity of dealing with maintenance because it is a significant source of savings and indirect benefits. The proposed maintenance policy meets all these conditions in view of the rapid responsiveness of the system. The core element of the proposal itself is predicting potential failures and the associated prevention (reactive) repairs or reconfiguration, which is responsible for operational change the trajectory. For future will be maintenance more and more required and needed than it is today. Today's classical maintenance will be in the future represented by sophisticated system. Therefore it is necessary to maintain high production quality and cost effective solutions. It is needed to solve the integration of reconfigurable maintenance systems which will bring businesses effective solutions for solving adverse situations.

\section{Acknowledgements}

This paper was made about research work support: Kega 064 ŽU - 4/2014.

\section{References}

[1] I. K. Kukushkin, B. Katalinic, P. Cesarec, R. Kettler: „Reconfiguration in self-organizing systems“ In: Annals of DAAAM for 2011 \& Proceedings of the 22nd International DAAAM Symposium "Intelligent Manufacturing \& Automation: Power of Knowledge and Creativity", Editor B.[ranko] Katalinic, ISSN 1726-9679, ISBN 978-3901509-83-4, pp 641-642, Vienna, Austria, Published by DAAAM International, Vienna, 2011

[2] Y. Huang, et. al.: "Task-Oriented Adaptive Maintenance Support Systems" In: Journal of Computing and Information Science in Engineering. 2015, Vol. 15, no. 3. ISSN 1530-9827

[3] M. Gregor, J. Herčko, P. Grznár: "The Factory of the Future Production System Research" In: ICAC2015 Proceedings of the 21 st International Conference on Automation and Computing, Glasgow, ISBN: 978-0-9926801$0-7$, p. 254-259 
[4] K. K. Mittal, P. K. Jain: „An Overview of Performance Measures in Reconfigurable Manufacturing System“ In: Procedia Engineering, DAAAM 2013; ISSN 1877-7058. - Vol. 69, (2013), online, p. 1125-1129.

[5] F. Hasan, P. K. Jain, D. Kumar: „Service Level as Performance Index for Reconfigurable Manufacturing System Involving Multiple Part Families“ In: Procedia Engineering, DAAAM 2013; ISSN 1877-7058. - Vol. 69, (2013), online, p. 814-821.

[6] L. Kubinec, M. Rakyta, P. Podhora: "Calculation maintenance costs by Zero based budgeting. In: Manufacturing systems today and tomorrow: 8th annual international conference. - Liberec: Technická univerzita, 2014. - ISBN 978-80-7494-150-4.

[7] Y-Ch. Choi, P. Xirouchakis: "A holistic production planning approach in a reconfigurable manufacturing system with energy consumption and environmental effects" In: International Journal of Computer Integrated Manufacturing. Vol. 28 no 4, 2015, ISSN 0951-192X, p. 379-394

[8] B. Mičieta, V. Biňasová: "Methodology of implementation energy efficiency in manufacturing" In: DAAAM international scientific book 2014. - ISBN 978-3-901509-98-8. - p. 357-364. (Scientific book. - ISSN 1726-9687).

[9] A. Gupta, P. K. Jain, D. Kumar: "Configuration selection of reconfigurable manufacturing system based on performance" In: International Journal of Industrial and Systems Engineering. Vol. 20, no. 2, 2015. ISSN 1748 5037, p. $209-230$

[10] W. E. Page: "Expert Systems for Maintenance Applications." 1992. Clemson Apparel Research Center

[11] L. Durica, P. Bubeník: "The structure of the intelligent manufacturing system architecture" In: InvEnt 2015 : Industrial engineering from integration to innovation : proceedings of the international conference : University of Žilina, 2015. - ISBN 978-80-554-1038-8. - p. 48-51.

[12] A. Gupta, P. K. Jain, D. Kumar: "Configuration selection of reconfigurable manufacturing system based on performance" In: International Journal of Industrial and Systems Engineering. Vol. 20, no. 2, 2015. ISSN 1748 5037, p. $209-230$

[13] V. Vyatkin: "Function blocks for embedded and distributed control systems design." ISA, New Zealand, 2011, 260 p., ISBN 978-1-936007-93-6

[14] M. Gregor, J. Spalek: "The optimistic exploration value function” In: INES 2015: 19th international conference on Intelligent engineering systems : proceedings : 2015 Bratislava, Slovakia. - [S.1.: IEEE], 2015. - ISBN 978-1-46737938-0, p. 119-123.

[15] P. Bubeník, F. Horák, V. Hančinský: “Acquiring knowledge needed for pull production system design through data mining methods" In: Communications : scientific letters of the University of Žilina. - ISSN 1335-4205. - Vol. 17, no. 3 (2015), p. 78-82.

[16] V. Botti, A. Giret: Anemona: "A multi-agent methodology for holonic manufacturing systems", London, 2008, 214 s., ISBN 978-1- 84800-309-5

[17] S. Dienst, F. Ansari, M. Fathi: "Integrated system for analyzing maintenance records in product improvement." In: The International Journal of Advanced Manufacturing Technology, Springer London, vol. 76, p. 545-564. ISSN 0268-3768

[18] J. Herčko, A Štefánik: "Komponenty a princípy konceptu Industry 4.0" In: ProIN : bimonthly CEIT. - ISSN 13392271. - Vol. 16, no. 2 (2015), s. 47-49.

[19] R. K. Mobley: "Maintenance Engineering Handbook." McGraw-Hill Professional; 8 edition. 2013. 672 p., ISBN 978-0-07-182661-7.

[20] P. Dariusz, M.Krajčovič: "Production system designing with the use of digital factory and augmented reality technologies" In: Progress in automation, robotics and measuring techniques : control and automation. - ISBN 9783-319-15795-5. - S. 187-196.

[21] L. Xiao, S. Song, X. Chen, D. W. Coit: "Joint optimization of production scheduling and machine group preventive maintenance" In: Reliability Engineering \& System Safety, v. 146, 2015. p. 68-78. ISSN 0951-8320

[22] D. Vališ, L. Žák, O. Pokora, P. Lánský: "Perspective analysis outcomes of selected tribodiagnostic data used as input for condition based maintenance" In: Reliability Engineering \& System Safety, v. 145, 2015. p. 231-242. ISSN 0951-8320

[23] A Farid, L Ribeiro:"An Axiomatic Design of a Multiagent Reconfigurable Mechatronic System Architecture" In: Industrial Informatics, IEEE Transactions on (Volume:11， Issue: 5 ), 2015, ISSN 1551-3203 